\title{
Fuzzy Optimization: Possibilistic linear equality system
}

\author{
S. K. Singh ${ }^{1}$, Gyan Mukherjee ${ }^{2}$, and Chiranjib Mukherjee ${ }^{3}$ \\ ${ }^{I}$ Department of Mathematics, College of Commerce, Patna(Magadh University)INDIA \\ ${ }^{2}$ Department of Mathematics, S.P.S. College, Vaishali (INDIA) \\ ${ }^{3}$ Research Scholar, Magadh University, Patna(INDIA)
}

\begin{abstract}
We consider linear (and quadratic) possibilistic programs and show that the possibility distribution of their objective function remains stable under small changes in the membership functions of the fuzzy number coefficients. We generalize Kovacs's results to PLES with(Lipschitzian) fuzzy numbers and flexible linear programs.

Key words: Linear Equality System, Fuzzy Numbers, Fuzzy set of feasible solutions, Zadeh's extension principle, Kovacs's results.
\end{abstract}

The linear equality system

\section{Introduction:}

or shortly,

$$
a_{i 1} x_{1}+\ldots .+a_{i n} x_{n}=b_{i}, \quad i=1, \ldots \ldots, m,
$$

$$
\mathrm{Ax}=\mathrm{b}
$$

where $a_{i j}, b_{i}$ and $x_{j}$ are real numbers. It is known that system (1) generally belongs to the class of ill-posed problems, so a small perturbation of the parameters $\mathrm{a}_{\mathrm{ij}}$ and $\mathrm{b}_{\mathrm{i}}$ may cause a large deviation in the solution.

A possibilistic linear equality system is

$$
\tilde{a}_{i 1} \mathrm{x}_{1}+\ldots \ldots \ldots+\tilde{a}_{i n} \mathrm{x}_{\mathrm{n}}=\tilde{b}_{i}, \quad \mathrm{i}=1, \ldots \ldots, \mathrm{m},
$$

or shortly,

$$
\tilde{A} \mathrm{x}=\tilde{b},
$$

where $\tilde{a}_{i j}, \tilde{b}_{i} \in \mathrm{F}(\mathrm{IR})$ are fuzzy quantities, $\mathrm{x} \in \mathrm{IR}^{\mathrm{n}}$, the operations addition and multiplication by a real number of fuzzy quantities are defined by Zadeh's extension principle and the equation is understood in possibilistic sense. Recall the truth value of the assertion " $\tilde{a}$ is equal to $\tilde{b}$ ”, written as $\tilde{a}=\tilde{b}$, denoted by Pos $(\tilde{a}=\tilde{b})$, is defined as

$$
\operatorname{Pos}(\tilde{a}=\tilde{b})=\sup \left\{\tilde{a}(\mathrm{t})^{\wedge} \tilde{b}(\mathrm{t})\right\}=(\tilde{a}-\tilde{b})(0) .
$$

We denote by $\mu_{\mathrm{i}}(\mathrm{x})=\operatorname{Pos}\left(\tilde{a}_{i 1 \mathrm{x}_{1}}+\ldots \ldots . .+\tilde{a}_{i n} \mathrm{x}_{\mathrm{n}}=\tilde{b}_{i}\right)$.

Following Bellman and Zadeh the fuzzy solution (or the fuzzy set of feasible solutions) of system (2) can be viewed as the intersection of the $\mu_{\mathrm{i}}$ 's such that

$$
\mu(\mathrm{x})=\min \left\{\mu_{1}(\mathrm{x}), \ldots \ldots ., \mu_{\mathrm{m}}(\mathrm{x})\right\} .
$$

A measure of consistency for the possibilistic equality system (2) is defined as

$$
\mu^{*}=\sup \left\{\mu(\mathrm{x}) \mid \mathrm{x} \in \operatorname{IR}^{\mathrm{n}}\right\} .
$$

Let $X^{*}$ be the set of points $x \in I^{n}$ for which $\mu(x)$ attains its maximum, if it exists. That is

$$
X^{*}=\left\{X^{*} \in I^{n} \mid \mu\left(x^{*}\right)=\mu^{*}\right\}
$$

If $\mathrm{X}^{*} \neq \emptyset$ and $\mathrm{x}^{*} \in \mathrm{X}^{*}$, then $\mathrm{x}^{*}$ is called a maximizing (or best) solution of (2).

If $\tilde{a}$ and $\tilde{b}$ are fuzzy numbers with $[\mathrm{a}]^{\alpha}=\left[\mathrm{a}_{1}(\alpha), \mathrm{a}_{2}(\alpha)\right]$ and $[\mathrm{b}]^{\alpha}=\left[\mathrm{b}_{1}(\alpha), \mathrm{b}_{2}(\alpha)\right]$ then their Hausdorff distance is defined as

$$
\mathrm{D}(\tilde{a}, \tilde{b})=\sup _{\alpha \in[0,1]} \max \left\{\left|\mathrm{a}_{1}(\alpha)-\mathrm{b}_{1}(\alpha)\right|,\left|\mathrm{a}_{2}(\alpha)-\mathrm{b}_{2}(\alpha)\right|\right\} .
$$

i.e. $\mathrm{D}(\tilde{a}, \tilde{b})$ is the maximal distance between the $\alpha$ - level sets of $\tilde{a}$ and $\tilde{b}$.

Let $\mathrm{L}>0$ be a real number. By $\mathrm{F}(\mathrm{L})$ we denote the set of all fuzzy numbers $\tilde{a} \in \mathrm{F}$ with membership function satisfying the Lipschitz condition with constant $\mathrm{L}$, i.e.

$$
\left|\tilde{a}(\mathrm{t})-\tilde{a}\left(\mathrm{t}^{\prime}\right)\right| \leq \mathrm{L}\left|\mathrm{t}-\mathrm{t}^{\prime}\right|, \forall \mathrm{t}, \mathrm{t}^{\prime} \in \mathrm{IR} .
$$

In many important cases the fuzzy parameters $\tilde{a}_{i j}, \tilde{b}_{i}$ of the system (2) are not known exactly 
and we have to work with their approximations $\tilde{a}_{i j}^{\delta}, \tilde{b}_{i j}^{\delta}$ such that

$$
\max \mathrm{D}\left(\tilde{a}_{i j}^{\delta}, \tilde{a}_{i j}^{\delta}\right) \leq \delta . \max \mathrm{D}\left(\tilde{b}_{i j}^{\delta}, \tilde{b}_{i j}^{\delta}\right)
$$

$\mathrm{i}, \mathrm{j}$

i

where $\delta \geq 0$ is a real number. Then we get the following system with perturbed fuzzy parameters

$$
\tilde{a}_{i 1}^{\delta} \mathrm{x}_{1}+\ldots \ldots .+\tilde{a}_{i n}^{\delta} \mathrm{x}_{\mathrm{n}}=\tilde{b}_{i}^{\delta}, \quad \mathrm{i}=1, \ldots \ldots, \mathrm{m}
$$

or shortly,

$$
\tilde{A}_{x}^{\delta} \mathrm{x}=\tilde{b}^{\delta} .
$$

In a similar manner we define the solution

$$
\mu^{\delta}(\mathrm{x})=\min \left\{\mu^{\delta}(\mathrm{x}), \ldots \ldots \ldots, \mu_{\mathrm{m}}^{\delta}(\mathrm{x})\right\}
$$

and the measure of consistency

$$
\mu^{*}(\delta)=\sup \left\{\mu^{\delta}(\mathrm{x}) \mid \mathrm{x} \in \operatorname{IR}^{\mathrm{n}}\right\},
$$

of perturbed system (7), where

$$
\mu_{\mathrm{i}}^{\delta}(\mathrm{x})=\operatorname{Pos}\left(\tilde{a}_{i 1}^{\delta} \mathrm{x}_{1}+\ldots \ldots+\tilde{a}_{i n}^{\delta} \mathrm{x}_{\mathrm{n}}=\tilde{b}_{i}^{\delta}\right)
$$

denote the degree of satisfaction of the $\mathrm{i}$-th equation at $\mathrm{x} \in \mathrm{IR}^{\mathrm{n}}$. Let $\mathrm{X}^{*}(\delta)$ denote the set of maximizing solutions of the perturbed system (7).

Kovacs showed that the fuzzy solution to the system (2) with symmetric triangular fuzzy numbers is a stable respect to small changes of centers of fuzzy parameters. Following fuller in the next theorem we establish a stability property (with respect to perturbations (6) of the solution of system (2).

Theorem A. Let $\mathrm{L}>0$ and and $\tilde{a}_{i j}^{\delta}, \tilde{b}_{i}, \tilde{b}_{i}^{\delta} \in \mathrm{F}(\mathrm{L})$. If (6) holds, then

$$
\left\|\mu-\mu^{\delta}\right\|_{\infty}=\sup _{\mathrm{x} \in \mathrm{R}^{\mathrm{n}}}\left|\mu(\mathrm{x})-\mu^{\delta}(\mathrm{x})\right| \leq \mathrm{L} \delta
$$

where $\mu(\mathrm{x})$ and $\mu^{\delta}(\mathrm{x})$ are the (fuzzy) solutions to systems (2) and (7), respectively.

Proof: It is sufficient to show that

$$
\left|\mu(\mathrm{x})-\mu^{\delta}(\mathrm{x})\right| \leq \mathrm{L} \delta
$$

for each $\mathrm{x} \in \operatorname{IR}^{\mathrm{n}}$ and $\mathrm{i}=1, \ldots \ldots, \mathrm{m}$. Let $\mathrm{x} \in \operatorname{IR}^{\mathrm{n}}$ and $\mathrm{i} \in\{1, \ldots \ldots, \mathrm{m}\}$ be arbitrarily fixed. From (3) it follows that

$$
\begin{aligned}
& \mu_{\mathrm{i}}(\mathrm{x})=\left(\sum_{j=1}^{n} \tilde{a}_{i j} \mathrm{x}_{\mathrm{j}}-\tilde{b}_{i}\right)(0), \\
& \mu_{\mathrm{i}}^{\delta}(\mathrm{x})=\left(\sum_{j=1}^{n} \tilde{a}_{i j}^{\delta} \mathrm{x}_{\mathrm{j}}-\tilde{b}_{i}^{\delta}\right)(0) .
\end{aligned}
$$

Applying, Let $\tilde{a}, \tilde{b}, \tilde{c}$, and $\tilde{d}$ be a fuzzy number. Then

$$
\begin{aligned}
& \mathrm{D}(\tilde{a}-\tilde{c}, \tilde{b}-\tilde{d}) \leq \mathrm{D}(\tilde{a}, \tilde{b})+\mathrm{D}(\tilde{c}, \tilde{d}), \text { we get } \\
& \mathrm{D}\left(\sum_{j=1}^{n} \tilde{a}_{i j} \mathrm{x}_{\mathrm{j}}-\tilde{b}_{i}, \sum_{j=1}^{n} \tilde{a}_{i j}^{\delta} \mathrm{x}_{\mathrm{j}}-\tilde{b}_{i}^{\delta}\right) \leq \\
& \sum_{j=1}^{n}\left|x_{j}\right| \mathrm{D}\left(\tilde{a}_{i j}, \tilde{a}_{i j}^{\delta}\right)+\mathrm{D}\left(\tilde{b}_{i}, \tilde{b}_{i}^{\delta}\right) \leq \delta\left(|\mathrm{x}|_{1}+1\right),
\end{aligned}
$$

where $|\mathrm{x}|_{1=}\left|\mathrm{x}_{1}\right|+\ldots \ldots+\left|\mathrm{x}_{\mathrm{n}}\right|$. Finally, by

if $\mathrm{D}(\tilde{a}, \tilde{b}) \leq \delta$ then

$$
\lambda \tilde{a} \in \mathrm{F}(\mathrm{L} /|\lambda|), \lambda \tilde{a}+\mu \tilde{b} \in \mathrm{F}(\mathrm{L} /|\lambda|+|\mu|)
$$

$\sup |\tilde{a}(\mathrm{t})-\tilde{b}(\mathrm{t})| \leq \mathrm{L} \delta$, we get

$$
\begin{aligned}
& \sum_{j=1}^{n} \tilde{a}_{i j} \mathrm{x}_{\mathrm{j}}-\tilde{b}_{i} \in \mathrm{F}\left(\mathrm{L} /|\mathrm{x}|_{1}+1\right), \\
& \left.\sum_{j=1}^{n} \tilde{a}_{i j}^{\delta} \mathrm{x}_{\mathrm{j}}-\tilde{b}_{i}^{\delta}\right) \in \mathrm{F}\left(\mathrm{L} /|\mathrm{x}|_{1}+1\right)
\end{aligned}
$$


and, therefore

$$
\begin{aligned}
& \left|\mu_{\mathrm{i}}(\mathrm{x})-\mu_{\mathrm{i}}^{\delta}(\mathrm{x})\right|=\left|\left(\sum_{j=1}^{n} \tilde{a}_{i j} \mathrm{x}_{\mathrm{j}}-\tilde{b}_{i}\right)(0)-\left(\sum_{j=1}^{n} \tilde{a}_{i j}^{\delta} \mathrm{x}_{\mathrm{j}}-\tilde{b}_{i}^{\delta}\right)(0)\right| \leq \\
& \sup _{\mathrm{t}}\left|\left(\sum_{j=1}^{n} \tilde{a}_{i j} \mathrm{x}_{\mathrm{j}}-\tilde{b}_{i}\right)(\mathrm{t})-\left(\sum_{j=1}^{n} \tilde{a}_{i j}^{\delta} \mathrm{x}_{\mathrm{j}}-\tilde{b}_{i}^{\delta}\right)(\mathrm{t})\right| \leq \\
& \mathrm{L} /|\mathrm{x}|_{1}+1 \times \delta\left(|\mathrm{x}|_{1}+1\right)=\mathrm{L} \delta .
\end{aligned}
$$

Which proves the theorem.

From (8) it follows that

$$
\left|\mu^{*}-\mu^{*}(\delta)\right| \leq \mathrm{L} \delta
$$

where $\mu^{*}, \mu^{*}(\delta)$ are the measures of consistency for the systems (2) and (7), respectively. It is easily checked that in the general case $\tilde{a}_{i j}, \tilde{b}_{i} \in \mathrm{F}(\mathrm{IR})$ the solution to possibilistic linear equality system (2) may be unstable (in metric $\mathrm{C}_{\infty}$ ) under small variations in the membership function of fuzzy parameters (in metric $\mathrm{D}$ ).

To find a maximizing solution to a possibilistic linear equality system (2), then according to Negoita, we solved the following optimization problem

$$
\begin{aligned}
& \operatorname{maximize} \quad \lambda \\
& \mu_{1}\left(\mathrm{x}_{1}, \ldots \ldots, \mathrm{x}_{\mathrm{n}}\right) \geq \lambda, \\
& \ldots \ldots \ldots \ldots \ldots \ldots \ldots, \ldots \ldots, \ldots \\
& \mu_{\mathrm{m}}\left(\mathrm{x}_{1}, \ldots \ldots, \mathrm{x}_{\mathrm{n}}\right) \geq \lambda, \\
& \mathrm{x} \in \mathrm{IR}^{\mathrm{n}}, 0 \leq \lambda \leq 1 .
\end{aligned}
$$

The solutions of problem (9) generally requires the use of nonlinear programming techniques, and could be tricky. However, if the fuzzy numbers in (2) are of trapezoidal form, then the problem(9) turns into a quadratically constrained programming problem.

Even though the fuzzy solution and the measure of consistency of system (2) have a stability property with respect to changes of the fuzzy parameters, the behavior of the maximizing solution towards small perturbations of the fuzzy parameters can be very fortuitous, i.e., supposing that, $\mathrm{X}^{*}$, the set of maximizing solutions to system (2) is not empty, the distance between $x^{*}(\delta)$ and $X^{*}$ can be very big, where $x^{*}(\delta)$ is a maximizing solution of the perturbed possibilistic equality system (7).

Consider the possiblistic equality system (2) with fuzzy numbers of symmetric triangular form

or shortly

$$
\left(a_{i 1}, \alpha\right) x_{1}+\ldots . .+\left(a_{i n}, \alpha\right) x_{n}=\left(b_{i}, \alpha\right), i=1, \ldots \ldots, m,
$$

$$
(A, \alpha) x=(b, \alpha)
$$

Then following Kovacs and Fuller the fuzzy solution of (10) can be written in a compact form

$$
\mu(\mathrm{x})= \begin{cases}1 & \text { if } \mathrm{Ax}=\mathrm{b} \\ 1-\|\mathrm{Ax}-\mathrm{b}\|_{\infty} / \alpha\left(|\mathrm{x}|_{1}+1\right) & \text { if } 0<\|\mathrm{Ax}-\mathrm{b}\|_{\infty}<\alpha\left(|\mathrm{x}|_{1}+1\right) \\ 0 & \text { if }\|\mathrm{Ax}-\mathrm{b}\|_{\infty}>\alpha\left(|\mathrm{x}|_{1}+1\right)\end{cases}
$$

where,

if

$$
\|A x-b\|_{\infty}=\max \left\{\left|\left(a_{1}, x\right)-b_{1}, \ldots \ldots,\right|\left(a_{m}, x\right)-b_{m} \mid\right\} .
$$

$$
[\mu]^{1}=\left\{\mathrm{x} \in \operatorname{IR}^{\mathrm{n}} \mid \mu(\mathrm{x})=1\right\} \neq \emptyset
$$

then the set of maximizing solutions, $X^{*}=[\mu]^{1}$, of $(10)$ coincides with the solution set, denoted by $X^{* *}$, of the crisp system $\mathrm{Ax}=\mathrm{B}$. The stability theorem for system (10).

Lemma 1. If

holds, then

$$
\mathrm{D}\left(\tilde{A}, \tilde{A}^{\delta}\right)=\max _{\mathrm{i}, \mathrm{j}}\left|\mathrm{a}_{\mathrm{ij}}-\mathrm{a}_{\mathrm{ij}}^{\delta}\right| \leq \delta, \mathrm{D}\left(\tilde{b}, \tilde{b}^{\delta}\right)=\max _{\mathrm{i}}\left|\mathrm{b}_{\mathrm{i}}-\mathrm{b}_{\mathrm{i}}^{\delta}\right| \leq \delta
$$

$$
\left\|\mu-\mu^{\delta}\right\|_{\infty}=\sup _{\mathrm{x}}\left|\mu(\mathrm{x})-\mu^{\delta}(\mathrm{x})\right| \leq \delta / \alpha
$$


where $\mu(\mathrm{x})$ and $\mu^{\delta}(\mathrm{x})$ are the fuzzy solutions to possibilistic equality systems

$$
(\mathrm{A}, \alpha) \mathrm{x}=(\mathrm{b}, \alpha)
$$

and,

$$
\left(\mathrm{A}^{\delta}, \alpha\right) \mathrm{x}=\left(\mathrm{b}^{\delta}, \alpha\right) \text {, respectively. }
$$

Lemma2. Let $\tilde{a}_{i j}, \tilde{a}_{i j}^{\delta}, \tilde{b}_{i}, \tilde{b}_{i}^{\delta} \in \mathrm{F}$ be a fuzzy numbers. If (6) holds, then

$\left\|\mu-\mu^{\delta}\right\|_{\infty} \leq \mathrm{w}(\delta)$

where $\mathrm{w}(\delta)$ denotes the maximum of modulus of continuity of all fuzzy coefficients at $\delta$ in (2) and (7).

\section{Concluding Remarks:-}

In this paper we have shown that the solution and the measure of consistency of the system (10) have a stability property. The behavior of the maximizing solution towards a perturbation of the fuzzy parameters has been described. Also we find Kovacs's results to PLES with (Lipschitzian) fuzzy numbers and flexible linear programs.

\section{References:}

[1]. E.B.Ammar and M.A.El-HadyKassem, on stability anslysis of multicriteria L.P Problems with fuzzy parameters, Fezzy Sets and Syatems, 1999 PP.331-334.

[2]. J.F.Brule,Fuzzy Systems - a tutorial, 1985.

[3]. J.J.Buckley, solving possibilistic linear programming problems, Fezzy Sets and Syatems, 1989, PP. 329-341.

[4]. E. Canestrelli, S. Giove and R.Fuller, sensitivity analysis in possibilistic quadratic programming, Fezzy Sets and Syatems, 1996, PP.51-56.

[5]. C.Carlsson and R. Fuller, optimization under fuzzy if-then rule, Fezzy Sets and Syatems, 1999.

[6]. P.Czyzak and R. Slowinski, possibilistic construction of fuzzy outranking relation for multiplecriteria ranking, Fezzy Sets and Syatems, 1996, PP.123-131.

[7]. M. Delgado, J. Kacprzyk, J.L.Verdegay and M.A.Vila eds, Fuzzy Optimization, Recent Advances, Physica- Verlag, 1994.

[8]. D. Dubois and H. Prade, systems of linear fuzzy constraints, Fezzy Sets and Syatems, 1980, PP.37- 48.

[9]. D. Dubois and H. Prade, Possibility Theory, Plenum Press, New York, 1988.

[10]. D. Dubois and H. Prade, Fezzy Sets and Syatems: Theory and Applications, Academic Press, London, 1980. 